\title{
Survey of Online Systems in U.S. Academic Libraries
}

\section{John A. Camp, Grace Agnew, Christina Landram,}

\section{Jane Richards, and Judith M. Shelton}

\begin{abstract}
A survey of online systems in U.S. academic libraries was conducted to gather information on acquisitions, serials, circulation, cataloging, interlibrary loan, and integrated systems. Libraries reported on present systems and future plans, methods of financing, and use of systems personnel, as well as backup systems, type of computer, source for system, and functions within systems. Survey results indicate that $15 \%$ of libraries have no online systems and that $16.2 \%$ plan no additional ones. Cataloging and interlibrary loan units are the most frequently automated.
\end{abstract}

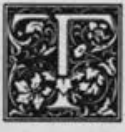

he predominance of automation as a theme in the library literature attests to the fact that libraries are turning increasingly to online systems for a variety of functions. Joseph R. Matthews documents this in his annual review of the automated library systems marketplace (see table 1 ). This pattern of growth promises to continue.

A factual presentation of current installations and future plans was the goal of this survey. It was limited to online systems. A state-of-the-art review of online systems was also deemed to be important to supply a historical perspective.

In view of the bewildering variety of systems and the time and expense of implementing them, it would seem to be desirable for libraries to learn about the choices made by comparable institutions. However, the magnitude of the project precluded an investigation into the more subjective motives and factors influencing libraries in their choice of systems.

\section{METHODOLOGY AND HYPOTHESES}

A search of Library Literature and the
ERIC and LISA databases led to numerous studies of particular systems or reports of the experiences of individual institutions. We discovered several state surveys, but they did not provide the depth we were seeking. One recent survey was limited to members of the Association of Research Libraries. ${ }^{1}$ The present study concerns the extent of online automation in libraries of four-year academic institutions in the United States.

Several general hypotheses provided the basis for a questionnaire:

1. Significant online automation is in place in academic libraries.

2. Where online automation does not exist, it is anticipated.

3. Large libraries are more likely than small libraries to be automated.

4. Systems developed in-house will probably be found in large libraries.

5. Funding may come from a variety of sources, but the regular library budget is not a major source.

6. Participation in bibliographic utilities is extensive.

An 83-item questionnaire was designed to test these hypotheses. The question-

John A. Camp, Grace Agnew, Christina Landram, Jane Richards, and Judith M. Shelton are at the Pullen Library Catalog Department, Georgia State University, Atlanta, Georgia 30303-3081. 
TABLE 1

TURNKEY AUTOMATED LIBRARY SYSTEMS

\begin{tabular}{ccc}
\hline \hline & $\begin{array}{c}\text { New } \\
\text { Installations }\end{array}$ & $\begin{array}{c}\text { Number of } \\
\text { Worldwide } \\
\text { Installation }\end{array}$ \\
\hline 1982 & 81 & 365 \\
1983 & 99 & 475 \\
1984 & 167 & 769 \\
1985 & 235 & 1109 \\
\hline
\end{tabular}

Sources: Joseph R. Matthews, Library Joumal, Mar. 1983, May 1984, Apr. 1985, Apr. 1986.

naire solicited general information (library size, number of monographic titles acquired annually, whether the responding institution belonged to a bibliographic utility, and whether a systems specialist was employed or available) and information on seven specific online applications: acquisitions, union list of serials, serials control, interlibrary loan, circulation, machine-readable cataloging, and online public access catalogs. For each of these applications, standard comparison information was requested, such as method of funding, type of computer on which the system is run, type of system (vendor, bibliographic utility, developed in-house, etc.). This included specific questions about individual systems; for example, the extent of interlibrary loan activity (both borrowing and lending), methods of access for online public catalogs, and specific features of acquisitions systems. Finally, the questionnaire sought information on integrated systems and their capabilities, including how long systems had been in place, or if not yet implemented, the projected timetable for installation.

This questionnaire was first tested by surveying online automation in the state of Georgia. Survey results were published in the Georgia Librarian. ${ }^{2}$ Although the basic content of the questionnaire remained the same, minor changes in wording or question sequence were made after the Georgia study.

The sample population was taken from a Bowker list of academic institutions and was limited to 300 four-year institutions, excluding junior colleges and technical schools. The questionnaire was administered through a mailing in June and Sep- tember 1985 . A full $73.7 \%$ (221) were returned, and $70 \%$ of the total sent (210) were determined to be usable. The data collected were tabulated using the frequency and cross-tab procedures of the Statistical Package for the Social Sciences, Version 10 (SPSS-X). The significance of relationships in the cross tabs was measured using the chi-square statistic. Statistical significance is indicated by the equations $\mathrm{P}<.001, \mathrm{P}<.01$, and $\mathrm{P}<.05$, with $\mathrm{P}<.001$ demonstrating the highest degree of significance.

\section{"One of our basic hypotheses was that size would influence the online automation decisions made by li- braries."}

The survey was designed to reveal the extent of online automation in academic libraries and to determine the direction academic libraries are taking with respect to online automation.

\section{RESPONDENTS' CHARACTERISTICS}

One of our basic hypotheses was that size would influence the online automation decisions made by libraries. Of the 210 libraries responding, $65.2 \%$ (137) are small libraries with 250,000 volumes or fewer; another $26.2 \%(55)$ are classed as medium-sized libraries with between 250,000 and 1 million volumes; and $8.6 \%$ (18) are large libraries with more than 1 million volumes (see table 2 ).

\section{TABLE 2}

SIZE OF LIBRARIES RESPONDING TO

THE SURVEY BY VOLUMES IN THE COLLECTION $(n=210)$

\begin{tabular}{lrr}
\hline \hline & No. & \multicolumn{1}{c}{$\%$} \\
\hline Small (0-250,000 volumes) & 137 & 65.2 \\
Medium (250,001-1,000,000 volumes) & 55 & 26.2 \\
Large (More than 1,000,000 volumes) & 18 & 8.6 \\
\hline
\end{tabular}

All of the small and nearly all (52) of the medium-sized libraries acquire fewer than 25,000 volumes a year while 3 medium and 15 large libraries acquire more than $25,000(\mathrm{P}<.001)$. Seven respondents re- 
TABLE 3

CHARACTERISTICS OF LIBRARIES REPORTING ONLINE SYSTEMS, FOR SELECTED APPLICATIONS

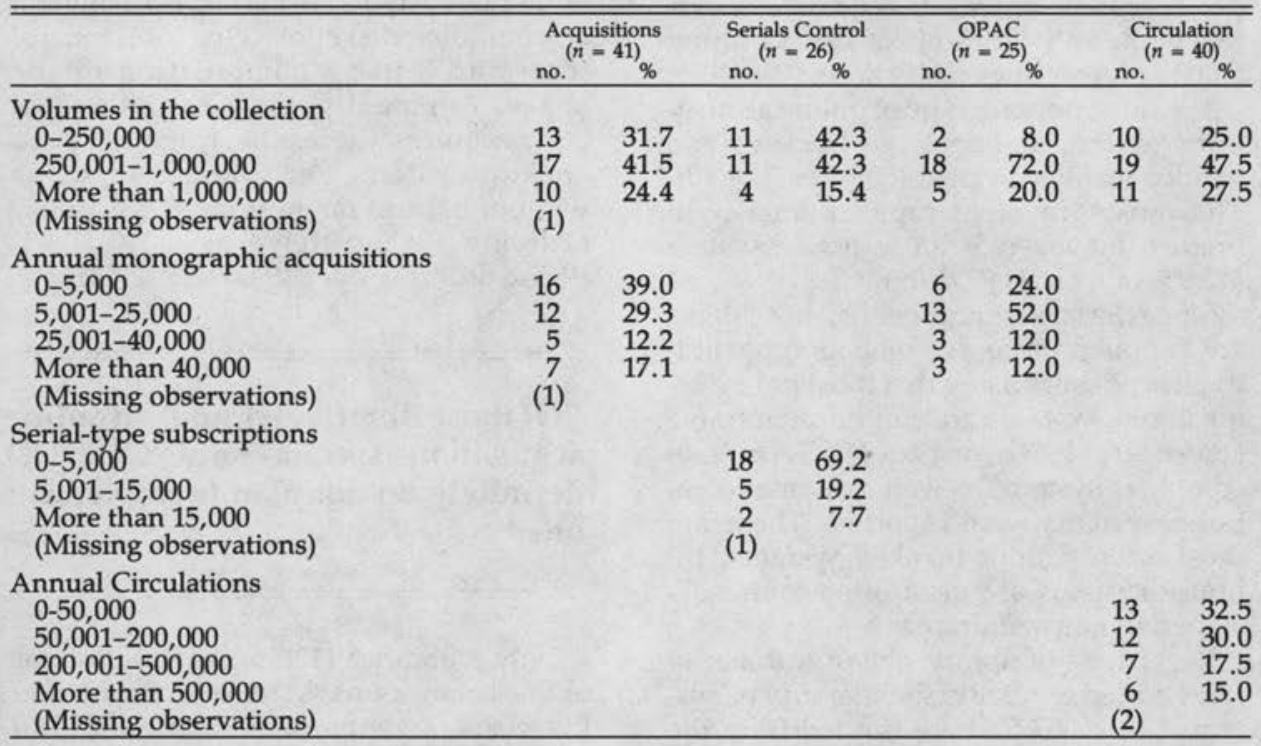

Note: Percentages may not equal $100 \%$ due to rounding.

port annual acquisitions in excess of 40,000 titles (see table 3).

More than $80 \%$ of the responding libraries (166) use a bibliographic utility, and $92.9 \%$ (156) of these use OCLC. All of the large and 53 of the medium-sized libraries use a bibliographic utility. Although a majority of small libraries do use one, $29.6 \%$ ( 40 of 135$)$ do not $(\mathrm{P}<.001)$ (see table 4).

\section{TABLE 4}

BIBLIOGRAPHIC UTILITY MEMBERSHIP OF LIBRARIES RESPONDING TO THE SURVEY $(n=210)$

\begin{tabular}{lrr}
\hline \hline & no. & \multicolumn{1}{c}{$\%$} \\
\hline None & 42 & 20.0 \\
OCLC & 156 & 74.3 \\
RLIN & 5 & 2.4 \\
WLN & 5 & 2.4 \\
More than 1 & 2 & 1.0 \\
\hline
\end{tabular}

Note: Percentages may not equal $100 \%$ due to rounding.

Sixty-two responding libraries report having a systems specialist. In 54 (85.7\%) of these institutions, this specialist is a member of the library staff. As the size of the library increases, so does the probabil- ity of having a systems specialist, ranging from $13.4 \%$ ( 18 of 134$)$ for small libraries to $88.9 \%$ (16 of 18$)$ for large libraries $(\mathrm{P}<.001)$.

\section{ACQUISITIONS}

Of the 209 libraries responding to this set of questions, $169(80.9 \%)$ do not have an online acquisitions system. Of the $41 \mathrm{li}$ braries who do (19.5\%), 20 use a system supplied through a bibliographic utility. Since 156 of 168 libraries responding to a question on utility membership belong to OCLC, it is not surprising that $75 \%$ of those 20 libraries use a system supplied by OCLC. The next most prevalent system is a vendor turnkey system, used by ten libraries $(25 \%)$, followed closely by eight libraries $(20 \%)$, using a system developed in-house.

A greater percentage of large libraries than small ones have an online acquisitions system. Of libraries with more than 250,000 volumes, $38 \%$ ( 28 of 73 ) utilize this type of automation while only $9.6 \%$ (13 of 136) of those with fewer than 250,000 have one $(\mathrm{P}<.001)$. This is corroborated by a 
comparison based on the number of titles acquired each year. A full $100 \%$ of those libraries acquiring more than 40,000 titles per year have an online acquisitions system while only $11.9 \%$ (16 of 135$)$ acquiring 5,000 or fewer titles per year do $(\mathrm{P}<.001)$.

The most popular type of online acquisitions system among large libraries is a vendor turnkey system $(50 \%$, or 5 of 10$)$. The most prevalent type in smaller libraries, however, is an in-house system $(42.9 \%$ or 6 of 14$)(\mathrm{P}<.05)$.

Since the largest number (20) of systems are supplied through a bibliographic utility, it is not surprising that most online acquisitions systems are run on mainframe computers $(46.3 \%$, or 19 of 41 ). Ten microcomputer systems as well as 10 minicomputer systems were reported. These are most often vendor turnkey systems. Inhouse systems are most often found designed to use mainframes.

Regardless of library size or number of titles added annually, the majority of systems $(23$, or $57.5 \%)$ are funded from the regular library budget rather than from special allocation by the institution $(5$, or $12.5 \%)$, grants (2, or $5 \%)$, the institution's computer center budget $(4$, or $10 \%)$, or a combination of these $(6$, or $15 \%)$.

All libraries but one ( $97.5 \%)$ order materials through the system, and this one plans to add this function. In-process control, accounting, and generation of reports are next most common functions of online systems. Thirty-four libraries (85\%) currently have these capabilities. Twentythree libraries $(57.5 \%)$ have claiming capability online and the same number have vendor control. Only 12 libraries (25\%) report online interface with vendors, and only 7 systems are expected to add this feature. The least common module is binding, which 5 of $40(12.5 \%)$ report having. Only 3 institutions plan to add this function to their acquisitions system.

If current plans are implemented, the relative position among functions will remain the same. Perhaps the most notable discovery is that 4 libraries $(10 \%)$ have no plans to implement an accounting function, and 5 libraries (12.5\%) do not plan for the generation of reports.

Twenty-two of 41 respondents $(53.7 \%)$ maintain no backup for their system. Of those that do, a backup in hard copy is the most common format (12, or $29.3 \%)$. Another two systems are backed up using microcomputer diskettes. One uses microform and 3 use a combination of the above. Apparently, the more titles a library acquires, the less likely it is to have a backup system. Percentages of those without backup range from $11.8 \%$ (those ordering 5,000 or fewer titles) to $100 \%$ (those ordering over 40,000$)(\mathrm{P}<.05)$.

\section{"Of those libraries without an online acquisitions system, only 20 (12.1\%) definitely do not plan to implement one."}

Only 5 libraries (12.5\%) have had their online acquisitions systems for more than five years. Twenty-three libraries (57.5\%) have had their systems for one to five years and $12(30 \%)$ report having online acquisitions for less than a year. Libraries with in-house systems ( 3 of 7 , or $42.9 \%$; $\mathrm{P}<.05$ ) are more likely to have had their systems in place for more than five years, and since, as noted above, smaller libraries are more likely to have in-house systems, it could be assumed that it is the smaller libraries that have had online acquisitions systems for the longest period. However, that statistic showed no significance $(\mathrm{P}=.4482)$.

Of those libraries without an online acquisitions system, only $20(12.1 \%)$ definitely do not plan to implement one. All the largest libraries do plan to have one, and more medium ( 31 of 38 or $81.8 \%$ ) than small libraries (48 of 119 or $38.7 \%$ ) have such plans. $(\mathrm{P}<.001)$ Seventy-eight of 87 libraries $(89.6 \%)$ planning to add such a system will do so within five years.

\section{SERIALS CONTROL SYSTEM}

Only $26(12.5 \%)$ of the 208 responding libraries have online serials control systems and, surprisingly, no single type predominates. Six $(23.1 \%)$ are supplied through a commercial service (such as Faxon), 7 sys- 
tems $(26.9 \%)$ were developed in-house, and $8(30.8 \%)$ are supplied through a bibliographic utility. Three systems $(11.5 \%)$ are vendor turnkey and $2(7.7 \%)$ are combination vendor/in-house. Only 3 of 25 $(12 \%)$ online serials control systems have been in use for more than five years; 13 $(52 \%)$ have been in use between one and five years; $9(36 \%)$ were implemented during the last year.

Funding for 19 of the 26 systems (73.1\%) came from the library budget. Four $(15.4 \%)$ libraries reported funding through the computer center budget and 2 (7.7\%) through special allocation from the parent institution. One respondent listed a combination of these sources. The fact that 17 of the $26(65.4 \%)$ are run on mainframe computers is not surprising, because in 9 cases $(34.6 \%)$ a computer is shared with the parent institution, and at 13 institutions the computer is provided by a bibliographic utility, commercial service, or vendor. Only 4 systems $(15.4 \%)$ run on computers dedicated solely to the library.

Of the 9 system features investigated, none is functional in all 26 of the libraries with online serials control systems. The three most common are check-in $(22$, or $84.6 \%)$, claiming $(19$, or $73.1 \%)$ and report generation $(18$, or $69.2 \%)$. The other 6 functions are common to slightly more than one-third of the libraries responding: 11 libraries report accounting and routing; 10 have ordering and binding modules; 9 have vendor control; and 8 have an online interface with vendors. Even plans for future development will not result in a common feature for serials control for all 26 libraries. Even the check-in module was excluded by at least one library from plans for the future as listed. If implementation plans are carried out as reported, the current three most common functions will continue to be prevalent, in the same order: check-in ( 25 or $96.2 \%$ ); claiming ( 22 or $84.6 \%$ ); and report generation (19 or $73.1 \%)$.

Serials holdings information is available online to the public in only 8 of the 26 systems $(30.8 \%)$, but 24 libraries $(92.3 \%)$ issue computer-produced serials holdings lists. When the system is down, 11 libraries
(42.3\%) provide no backup, and of those that do, hard copy is the backup of choice (11).

\section{UNION LIST OF SERIALS}

Seventy-three of the 204 responding libraries $(35.8 \%)$ participate in an online union list of serials. More than half $(44$, or $60.3 \%$ ) of these systems are provided by a bibliographic utility, and vendors provide only $4(5.5 \%)$ of those reported. The regular library budget was the largest single source of funding (22), although 21 libraries do use some combination of regular budget, special allocation, and/or outside grant.

The most common type of computer cited for union lists is a mainframe ( 39 of 69 ). A significant 20 respondents did not know what type of computer is used by their institution. In only 8 of the 58 responses to the question of ownership did the computer belong to just one member. In a majority of cases ( 41 of 68 , or $60.3 \%$ ) the machine-readable record could be input or updated by the local institution. Hard-copy backup outnumbers microform two to one ( 30 to 15$)$ and 9 of 69 systems $(13 \%)$ use a combination of these two. Nine systems provide no backup.

\section{MACHINE-READABLE RECORDS}

More respondents use online systems for current cataloging than for any other online activity. Just over three-fourths of the respondents, (162 of 209 , or $77.55 \%$ ) have current cataloging records in machine-readable form: the remaining $22.5 \%$ do not. Of those who do, $147(90 \%)$ utilize a bibliographic utility for this function. While it is rare for libraries to have all cataloging records in machine-readable form ( 5 of 190 , or $2.6 \%$ ), it is noteworthy and somewhat surprising that a considerable number of respondents ( 25 of 190 or $13.2 \%$ ) have no cataloging records at all in machine-readable form. Bibliographic utilities still have growth prospects!

Current or planned conversion of records into machine-readable form was reported by $150(76.1 \%)$ of 197 respondents. The preferred method of conversion is through a bibliographic utility (96 of 161 respondents, or $59.6 \%$ ) and the conver- 
sion will most often be done by in-house personnel. Nearly a quarter of the respondents $(22.4 \%)$ do not know how the conversion will be done, and only 4 libraries $(2.5 \%)$ are planning to use a vendor.

\section{"Only 25 of the 208 libraries re- sponded affirmatively to the ques- tion of whether they have an online public access catalog."}

There is a distinct positive correlation between the size of a library, as measured by the number of volumes already in the collection $(\mathrm{P}<.001)$ or by the number of volumes added annually $(\mathrm{P}<.001)$, and whether any of its records are in machinereadable form. When size is defined by the number of volumes in the collection, $66.9 \%$ (91 of 137) of small libraries have machine-readable records, while $96.4 \%$ (53 of 55) of medium libraries do. All 18 large libraries have records in this form. When size is defined by annual acquisitions, the same pattern emerges. Among the 134 libraries adding 5,000 or fewer titles, $91(67.9 \%)$ have machine readable records. For the 57 adding 5,000 to 25,000 titles the percentages rise to 93 (or $53 \mathrm{li}$ braries), and all 18 libraries adding more than 25,000 titles have them.

\section{ONLINE PUBLIC ACCESS CATALOGS (OPACs)}

Only 25 of the 208 libraries responded affirmatively to the question of whether they have an online public access catalog. This means that only slightly over $12 \%$ have automated in this way. However, 119 of 183 libraries $(65 \%)$ currently without an OPAC plan to implement one, and the percentage rises in direct proportion to the percentage of machine-readable records they possess.

Two of 42 respondents $(4.8 \%)$ with $76 \%-99 \%$ of their cataloging records in machine-readable form do not plan an online catalog; nor does there seem to be any relationship between the percentage of records in machine-readable form and having an OPAC $(\mathrm{P}=.1125)$. The fact that only one of the 5 libraries with $100 \%$ of their records in machine-readable form actually has an online catalog may simply illustrate that online catalogs are relatively new and still in the planning stage.

Vendor turnkey systems are the most prevalent type of catalog $(67 \%$, or 16 of 25$)$ followed, in order, by a combination of types, a bibliographic utility or "other," and in-house systems. Half of these catalogs have been in place less than a year and only 1 respondent has had an online public access catalog for more than five years.

Funding for the online catalog was accomplished most often through a special allocation from the parent institution. This was true for 11 of 25 respondents ( $44.0 \%)$. The next most common funding arrangement was through the regular library budget $(6$, or $24 \%)$, followed by outside grants $(4$, or $16 \%)$, and a combination of sources $(4$, or $16 \%)$.

Minicomputers and mainframe systems are used equally for library automation (12 of 25 , or $48 \%$ for each); only one library has a micro-based system. Thirteen of 25 computers $(52 \%)$ are dedicated to library use only while 6 computers are shared with parent institutions and 6 computers are provided by vendors. Hard copy is the backup of choice in 11 of 25 cases (44\%), followed by 6 respondents who use microform $(24 \%)$, 1 who utilizes microcomputer diskette $(4 \%)$, and 1 only reporting "other."

The most prevalent capability of online public access catalogs is the display of holdings data. A full $92 \%$ (23 of 25 ) have this in place, and the remaining two libraries plan to implement this feature. Three times as many libraries have online catalog maintenance as have authority control (19 versus 6), although $84 \%$ ( 21 of 25 ) of the libraries with online catalogs report that they will eventually have these functions available. Seventy-six percent of the libraries (19 of 25) either currently have or plan to have cross-references visible to the public, online interface with a bibliographic utility, and the capability of gener- 
ating reports from the system. Crossreferences invisible to the public and set logic are or will be implemented in fewer than half the systems: 10 libraries ( $40 \%$ ) either have or plan to have the former, while 11 of $24(45.8 \%)$ will eventually possess the latter. Of the 25 responding libraries, only one has all 8 systems capabilities and only one has as few as two. Eighteen $(72 \%)$ have at least 5 capabilities.

Libraries were queried about 8 search capabilities possible with an online catalog: author, title, author/title, subject, keyword, Boolean operators, call numbers, and other identification numbers (ISBN, LC card number, OCLC record number, etc.). Nine of the 25 libraries $(36 \%)$ with online catalogs have all 8 search capabilities, while $4(16 \%)$ have only 4 of these features. The other 12 libraries range between these extremes. All online catalogs search by author and title, while 19 of the 25 (76\%) allow users a combination author/title search. Twenty $(80 \%)$ can search by call number and by other identification numbers.

Of 183 libraries that currently do not possess an online public access catalog, $119(65 \%)$ plan to acquire one. Another 43 $(24.5 \%)$ are undecided, and only 21 off the $183(11.5 \%)$ without an online public access catalog state that they do not plan to have one. Seventy-six of 120 libraries (63.3\%) plan to acquire their catalog before five years have elapsed.

\section{INTERLIBRARY LOAN (ILL)}

Of 208 responding libraries, 159 (76.4\%) identify potential lenders of interlibrary loan material through an online system. When asked to specify the type of online system used, 6 of 181 respondents (3.3\%) indicated a vendor-supplied system, 29 (16\%) a library consortium, and 146 $(80.7 \%)$ a bibliographic utility. Because only 159 respondents stated that they use an online system, the 181 responses to this question indicate that some libraries use more than one online source to identify lenders. Of 170 responding libraries, 142 $(83.5 \%)$ actually handle interlibrary transactions online (borrowing and lending) and again the large majority (131 of 159 , or
$82.4 \%$ ) specify bibliographic utilities as the means, although more than one online system may be used. The use of an online ILL system increases with the number of items borrowed annually, but more significantly with the number loaned $(\mathrm{P}<.05)$. Hard-copy backup for ILL is used by 137 libraries (83.5\%), but 12 libraries $(7.3 \%)$ have no backup at all.

\section{"Nearly one-fifth of the 208 respond- ing libraries (19.2\%) have an online circulation system."'}

Of 64 libraries without an online interlibrary loan service, $21(32.8 \%)$ plan to implement such a system, $20(31.2 \%)$ do not, and $23(35.9 \%)$ are undecided. Fifteen of 22 libraries $(68.2 \%)$ with such plans will fulfill them within five years.

\section{CIRCULATION}

Nearly one-fifth of the 208 responding libraries $(19.2 \%)$ have an online circulation system. More than three-fourths of these $(77.5 \%)$ have either a vendor turnkey system $(52.5 \%)$ or a system developed inhouse $(25 \%)$. Whether a library has an online circulation system appears to be directly related to the size of the library. If one measures size in terms of volumes in the collection, $7.4 \%$ (10 of 135$)$ of the responding small libraries, $34.5 \%$ (19 of 55 ) of the medium, and $61.1 \%$ ( 11 of 18 ) of the large libraries have online circulation systems $(\mathrm{P}<.001)$. Considering the number of items circulated, the percentages range from $10.2 \%$ of the responding libraries circulating less than 50,000 annually (13 of 128 ) to $75 \%$ (6 of 8 ) of those circulating more than $500,000(\mathrm{P}<.001)$.

As with online public access catalogs, the greatest single source of funding for online circulation systems is a special allocation from the parent institution (17 of 40, or $42.5 \%)$. Nine ( $22.5 \%$ ) found the money for the system in the regular library budget while another 9 employed a combination of funding sources. 
Only 39 libraries responded to a question on the level of computer used to run the system and more than half ( 23 or $58.9 \%$ ) reported using a minicomputer. Fourteen libraries (35.9\%) use a mainframe system, and only 2 libraries $(5 \%)$ use a microcomputer. Whether the computer is reserved exclusively for the use of the library is related to the size of the computer $(\mathrm{P}<.01)$ and to the type of circulation system in use $(\mathrm{P}<.01)$. Thus, both of the microcomputers are used exclusively by the library but only 3 of $14(21.4 \%)$ mainframes are reserved for the library. Eight of $10(80 \%)$ libraries with systems developed in-house share the computer with the parent institution while 17 of 20 libraries (85\%) with vendor turnkey systems have exclusive use of the computer $(\mathrm{P}<.01)$.

In response to a question on circulation system capabilities, all but one of the 40 responding libraries $(97.5 \%)$ currently have a charge-out/charge-in function and can issue overdue notices to patrons. These features will eventually be operational in all systems described. Holds and delinquent patron status are both currently functional in 35 systems $(87.5 \%)$; one more library plans to add the latter. Thirty-four systems (85\%) generate statistics and 3 more will add this function. Charging out to reserves and billing are functions of 30 systems (75\%). These two functions are now planned for implementation in four libraries. Twenty-nine systems $(72.5 \%)$ can issue recall notices. Only 23 respondents $(57.5 \%)$ have incorporated interlibrary loan capabilities into their systems, and only 3 others plan to add this.

Vendor turnkey systems tend to offer more functions than in-house systems. In addition to charge-out/charge-in and overdue notice generation, which are common to all systems, the vendor turnkey systems offer other features by a margin of at least $30 \%$ to $50 \%$. Some of these features are recall notices, provided by $95.2 \%$ of vendor turnkey systems compared with $40 \%$ of in-house systems $(\mathrm{P}<.05)$, and delinquent patron status, offered by $100 \%$ of vendor turnkey systems and $70 \%$ of in-house systems $(\mathrm{P}<.01)$.

One hundred eight of the 164 respond- ing libraries (65.9\%) plan to implement an online circulation system, two-thirds within five years.

\section{INTEGRATED ONLINE SYSTEMS}

Fewer than $10 \%$ of the 201 libraries responding to this section have an integrated online system. The 17 respondents are distributed thus: 6 of 129 small libraries $(4.7 \%), 9$ of 54 medium ( $16.6 \%)$, and 2 of the 18 large libraries responding $(11.1 \%)(\mathrm{P}<.05)$. Ten of these 17 , or more than half $(58.8 \%)$, were vendor turnkey systems.

Of the 17 integrated systems reported, $15(88.2 \%)$ have an OPAC module, 13 (76.4\%) have a circulation module, 7 $(41.2 \%)$ have an acquisitions module, 6 $(35.3 \%)$ have an ILL module, $4(23.5 \%)$ provide for union listing of serials, and 3 $(17.6 \%)$ include a serials control module.

Nine $(52.9 \%)$ of the libraries began their integrated systems operation with the OPAC module. Survey findings indicate that implementation of an OPAC module is not related to the percentage of catalog records in machine-readable form; $75 \%$ of the 4 responding libraries with $25 \%$ or fewer of their records in machine-readable form, and $71.4 \%$ of the 7 with $75 \%$ or more in machine-readable form implemented an OPAC first. Three (17.6\%) systems began with the circulation module. Acquisitions, union list of serials, and interlibrary loan were each the first step in three cases.

Nine libraries have implemented their integrated online systems within the last year and another 8 reported establishing the system during the past five years. All 9 of the functional acquisitions modules were implemented less than a year ago.

Of 178 libraries without integrated systems, $96(53.9 \%)$ plan to implement them. Only 25 libraries (14.0\%) have no plans to acquire integrated systems, and $57(32 \%)$ are uncertain. Sixty-two of 97 responses $(63.9 \%)$ indicated plans to implement within five years.

\section{CONCLUSIONS}

This survey revealed that approximately $15 \%$ of the libraries responding currently have no online systems. Furthermore, 
$16.2 \%$ have no plans to add more online components. Size is certainly a factor. Of the $22.4 \%$ (47 of 210 ) who either do not plan any more systems or are uncertain, $91.5 \%(43)$ are small libraries $(\mathrm{P}<.001)$.

This survey reveals that the trends apparent from the Georgia pretest of the questionnaire are consistent nationwide. Online automation is most extensive in those applications with an external component; that is, applications where more than one institution is involved: shared cataloging through a bibliographic utility $(77.5 \%$, or 162 of 209$)$, interlibrary loan (76.4\%, or 159 of 208 ), or union lists of serials $(35.8 \%$, or 73 of 204$)$. The less common and more recently automated online applications are those involving internal functions: circulation, acquisitions, serials control, and online public access catalogs (see table 5). Integrated systems are the least numerous of all, reported by seventeen $(8.5 \%)$ of 201 libraries. As these figures also make clear, there is significant online automation already in place in academic libraries, and our first hypothesis was indeed valid.

If implementation plans for online systems are carried out by libraries as reported, the automation status in academic libraries will be increased by the following figures: acquisitions, $40.5 \%$ (85); serials control, $48.6 \%$ (102); online public access catalogs, $57.1 \%$ (120); interlibrary loan, $32.8 \%$ (21); circulation, $51.4 \%$ (108); and integrated systems, $53.9 \%$ (96). The hypothesis that online automation is anticipated where it does not presently exist also proved valid. Although a substantial number of systems are reportedly planned within one year, the majority are expected to be operational during the next one to five years.

\section{"The hypothesis that large libraries would be more likely to have the fi- nancial resources and personnel ex- pertise to develop their own online systems was not corroborated by the survey."'}

The hypothesis that large libraries would be more likely to have the financial resources and personnel expertise to develop their own online systems was not corroborated by the survey. In every instance, the data proved statistically insignificant; thus, no conclusions could be drawn relating in-house systems and library size. However, the data did support the hypothesis that large libraries are more likely to be automated than small li-

TABLE 5

NUMBER OF LIBRARIES REPORTING ONLINE

SYSTEMS OR PLANS FOR SYSTEMS FOR SELECTED

APPLICATIONS, WITH TIME FRAMES ${ }^{1}(n=210)$

\begin{tabular}{lcccccccc}
\hline \hline & \multicolumn{2}{c}{ Acquisitions } & \multicolumn{2}{c}{ Serials Control } & \multicolumn{2}{c}{ OPAC } & \multicolumn{2}{c}{ Circulation } \\
no. & no. & $\%$ & no. & no. & n \\
\hline Have an online system & 41 & 19.5 & 26 & 12.4 & 25 & 11.9 & 40 & 19.0 \\
$\quad$ Less than 1 year & $12^{2}$ & $29.3^{2}$ & $9^{3}$ & $34.6^{3}$ & $12^{4}$ & $48.0^{4}$ & $6^{5}$ & $15.0^{5}$ \\
1-5 years & $23^{2}$ & $56.1^{2}$ & $13^{3}$ & $50.0^{3}$ & $11^{4}$ & $44.0^{4}$ & $20^{5}$ & $50.0^{5}$ \\
More than 5 years & $5^{2}$ & $12.2^{2}$ & $3^{3}$ & $11.5^{3}$ & $1^{4}$ & $4.0^{4}$ & $14^{5}$ & $35.0^{5}$ \\
(Missing observations) & $\left(1^{2}\right)$ & & $\left(1^{3}\right)$ & & $\left(1^{4}\right)$ & & & \\
Plan an online system & 85 & 40.5 & 102 & 48.6 & 120 & 57.1 & 108 & 51.4 \\
Within 1 year & $10^{6}$ & $11.8^{6}$ & $16^{7}$ & $15.7^{7}$ & $17^{8}$ & $14.2^{8}$ & $17^{9}$ & $15.7^{9}$ \\
1-5 years & $68^{6}$ & $80.0^{6}$ & $78^{7}$ & $76.5^{7}$ & $76^{8}$ & $63.3^{8}$ & $73^{9}$ & $67.6^{9}$ \\
More than 5 years & $7^{6}$ & $8.2^{6}$ & $8^{7}$ & $7.8^{7}$ & $27^{8}$ & $22.5^{8}$ & $18^{9}$ & $16.7^{9}$ \\
Do not plan to install one & 20 & 9.5 & 22 & 10.5 & 21 & 10.0 & 20 & 9.5 \\
Do not know & 64 & 30.5 & 60 & 28.6 & 44 & 21.0 & 42 & 20.0 \\
\hline
\end{tabular}

\footnotetext{
Notes:

1 percentages may not equal $100 \%$ due to rounding

$2 \begin{aligned} & n=41 \\ & n=26\end{aligned}$

$3 n=26$

$n=25$
$n=26$

$5 n=40$ 
braries $(\mathrm{P}<.001)$, as table 6 shows.

The hypothesis that the regular library budget would not prove a major source of funding for online automation was based on the competition for dollars. In other words, it seemed likely that other sources would have to be found for funding in order to maintain services at their thencurrent levels. These levels may have been maintained, but the hypothesis proved invalid. The major source of funding for online automation in academic libraries has indeed been the regular library budget (see table 7).

This was the most frequently cited source in acquisitions systems, serials control, and union lists of serials ( 22 of 56 , or $39.3 \%$ ), and the second most cited source in circulation systems and online public access catalogs. For these last two, special allocations from the parent institution have provided the major source of funding (circulation; OPACs). This would suggest that institutions do indeed re- spond to patron needs. Outside grants were less frequently reported: 9 of 56 , or $16.1 \%$ of union lists of serials; 4 of 25 , or $16 \%$ of the OPACs; 2 of 41 , or $4.9 \%$ of acquisitions systems; and 2 of 40 , or $5 \%$ of circulation systems were funded in this manner. The computer center budget of the parent institution was responsible for only 4 of 41 , or $9.8 \%$ of acquisitions systems, and 4 of 26 , or $15.4 \%$ of serials controls systems.

Bibliographic utilities are the largest single provider of online systems, a finding that supports an initial hypothesis. This is not surprising for machine-readable records (147 of 162 , or $90.7 \%$ ) and interlibrary loan (146 of 181 , or $80.7 \%$ ), but it is also true for union lists of serials (44 of 172 , or $61.1 \%$ ), acquisitions (20 of 44 , or $45.4 \%$ ), and serials control ( 8 of 26 , or $30.8 \%$ ). Vendor turnkey systems are more prevalent in circulation modules ( 21 of 40 , or $52.5 \%$ ), OPACs ( 16 of 25 , or $64 \%)$, and integrated systems (10 of 17 , or $58.8 \%$ ). Systems de-

TABLE 6

EXTENT OF AUTOMATION BY LIBRARY SIZE

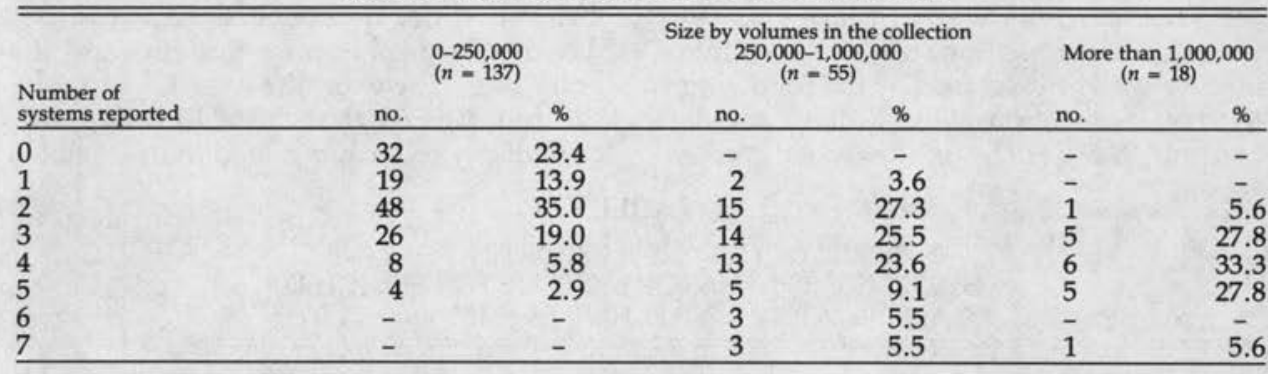

Note: Percentages may not equal $100 \%$ due to rounding.

TABLE 7

FUNDING OF ONLINE SYSTEMS REPORTED, FOR SELECTED APPLICATIONS

\begin{tabular}{|c|c|c|c|c|c|c|c|c|}
\hline & \multicolumn{2}{|c|}{$\begin{array}{c}\text { Acquisitions } \\
(n=41)\end{array}$} & \multicolumn{2}{|c|}{$\begin{array}{l}\text { Serials Control } \\
\quad(n=26)\end{array}$} & \multicolumn{2}{|c|}{$\begin{array}{c}\text { OPAC } \\
(n=25)\end{array}$} & \multicolumn{2}{|c|}{$\begin{array}{l}\text { Circulation } \\
(n-40)\end{array}$} \\
\hline $\begin{array}{l}\text { Regular library budget } \\
\text { Special allocation from }\end{array}$ & 23 & 56.1 & 19 & 73.1 & 6 & 24.0 & 9 & 22.5 \\
\hline parent institution & 5 & 12.2 & 2 & 7.7 & 11 & 44.0 & 17 & 42.5 \\
\hline Outside grant & 2 & 4.9 & - & - & 4 & 16.0 & 2 & 5.0 \\
\hline Computer center budget & $\overline{4}$ & 9.8 & 4 & 15.4 & - & - & 1 & 2.5 \\
\hline Combination of above & 6 & 14.9 & 1 & 3.8 & 4 & 16.0 & 9 & 22.5 \\
\hline Other & 1 & 2.4 & - & - & - & - & 2 & 5.0 \\
\hline
\end{tabular}

Note: Percentages may not equal $100 \%$ due to rounding. 
veloped in-house are the third most common, accounting for $9 \%$ (51 of 567) of the total responses. Consortia provide $16 \%$ (29 of 181) of interlibrary loan systems (see table 8).

The majority of acquisitions systems, union list of serials, and serials control use mainframe systems. Online public access catalogs use mainframes as often as minis. More circulation systems are run on minicomputers than mainframes. Microcomputer systems were reported least often (see table 9).

The preferred backup for each application is hard copy. Microforms appear to be the second backup of choice. Of note is the fact that 69 respondents to the questions on backup systems listed none at all. This is particularly surprising for online public access catalogs ( 6 of 25 , or $25 \%$ ) and circulation systems ( 9 of 40 , or $22.5 \%$ ), because of the importance of these systems to public service (see table 10).

In addition to providing a historical reference point in library automation, this study suggests further areas of investigation. One topic that deserves research is the organizational change that accompanies or results from automation. Automated systems have required that certain tasks be shifted, with the result that work flows more smoothly and efficiently. Since many tasks can be coordinated through a computer terminal, operations can be performed in different locations just by installing a terminal. Integrated

\section{TABLE 8}

SOURCE OF ONLINE SYSTEMS REPORTED, FOR SELECTED APPLICATIONS

\begin{tabular}{|c|c|c|c|c|c|c|c|c|}
\hline & \multicolumn{2}{|c|}{$\begin{array}{c}\text { Acquisitions } \\
(n=41)\end{array}$} & \multicolumn{2}{|c|}{$\begin{array}{l}\text { Serials Control } \\
\quad(n=26)\end{array}$} & \multicolumn{2}{|c|}{$\begin{array}{c}\text { OPAC } \\
(n=25)\end{array}$} & \multicolumn{2}{|c|}{$\begin{array}{c}\text { Circulation } \\
(n=40)\end{array}$} \\
\hline & no. & $\%$ & no. & $\%$ & no. & $\%$ & no. & $\%$ \\
\hline In-house & 8 & 19.5 & 7 & 26.9 & 1 & 4.0 & 10 & 25.0 \\
\hline Vendor turn-key & 10 & 24.4 & 3 & 11.5 & 16 & 64.0 & 21 & 52.5 \\
\hline Combination of above & 3 & 7.3 & 2 & 7.7 & 4 & 16.0 & 6 & 15.0 \\
\hline Bibliographic utility & 20 & 48.8 & 8 & 30.8 & 2 & 8.0 & - & - \\
\hline Other & - & - & $6^{1}$ & $23.1^{1}$ & $\overline{2}$ & 8.0 & 3 & 7.5 \\
\hline
\end{tabular}

Notes:

1 Commercial Service, e.g., EBSCO, FAXON, etc.

TABLE 9

TYPE OF COMPUTER USED FOR SELECTED ONLINE SYSTEMS REPORTED

\begin{tabular}{|c|c|c|c|c|c|c|c|c|}
\hline & \multicolumn{2}{|c|}{$\begin{array}{c}\text { Acquisitions } \\
(n=41)\end{array}$} & \multicolumn{2}{|c|}{$\begin{array}{c}\text { Serials Control } \\
(n=26)\end{array}$} & \multicolumn{2}{|c|}{$\begin{array}{c}\text { OPAC } \\
(n=25)\end{array}$} & \multicolumn{2}{|c|}{$\begin{array}{c}\text { Circulation } \\
(n=40)\end{array}$} \\
\hline & no. & $\%$ & no. & $\%$ & no. & $\%$ & no. & $\%$ \\
\hline Micro & 10 & 24.4 & 4 & 15.4 & 1 & 4.0 & 2 & 5.0 \\
\hline Mini & 10 & 24.4 & 2 & 7.7 & 12 & 48.0 & 23 & 57.5 \\
\hline Mainframe & 19 & 46.3 & 17 & 65.4 & 12 & 48.0 & 14 & 35.0 \\
\hline Don't know & 2 & 4.9 & 3 & 11.5 & - & - & 1 & 2.5 \\
\hline
\end{tabular}

TABLE 10

BACKUP FOR SELECTED ONLINE SYSTEMS REPORTED

\begin{tabular}{lrrrrrrrr}
\hline \hline & \multicolumn{2}{c}{$\begin{array}{c}\text { Acquisitions } \\
(n=41)\end{array}$} & \multicolumn{2}{c}{$\begin{array}{c}\text { Serials Control } \\
(n=26)\end{array}$} & no. & \multicolumn{2}{c}{$\begin{array}{c}\text { OPAC } \\
(n=25)\end{array}$} & \multicolumn{2}{c}{$\begin{array}{c}\text { Circulation } \\
(n=40)\end{array}$} \\
& no. & \multicolumn{1}{c}{$\%$} & no. & \% & no. & \% \\
\hline None & 22 & 53.7 & 11 & 42.3 & 6 & 24.0 & 9 & 22.5 \\
Hard copy & 12 & 29.3 & 11 & 42.3 & 11 & 44.0 & 19 & 47.5 \\
Microform & 1 & 2.4 & 1 & 3.8 & 6 & 24.0 & 1 & 2.5 \\
Micro diskette & 2 & 4.9 & 2 & 7.7 & 1 & 4.0 & 5 & 12.5 \\
Combination & 3 & 7.3 & 1 & 3.8 & - & - & 4 & 10.0 \\
Other & 1 & 2.4 & - & - & 1 & 4.0 & 2 & 5.0 \\
\hline
\end{tabular}

Note: Percentages may not equal $100 \%$ due to rounding. 
systems especially lend themselves to this; it would be useful to see how many libraries bypass the installation of separate systems in favor of an integrated one.

The most obvious project would be a follow-up study in five or six years to see if the projected automation actually takes place as reported in the present study. However, it is important to bear in mind, as suggested by the subtitle of several of Matthews' articles, that change may well alter all plans. Rapid changes in hardware and software may make existing systems obsolete. The introduction of new technology such as compact discs will have a tremendous impact. This can even extend to organizational changes such as OCLC's recent announcement of the deactivation of its present acquisitions system on January 1, 1989, and its replacement, already under way, by the ACQ350 system. A new serials control system, the SC 350 , is available. And there is a forthcoming OCLC 350 Services LAN (Local Area Network), which will allow several users to share the ACQ 350 and SC 350 systems.

So perhaps it is only safe to say that this is the situation at present. The future remains uncertain.

\section{REFERENCES}

1. Maxine K. Sitts, The Automation Inventory of Research Libraries 1985 (Washington, D.C.: Office of Management Studies, Association of Research Libraries, 1985).

2. Judith M. Shelton and others, "Online Systems in Georgia Academic Libraries," Georgia Librarian 22, no.3:58-59 (Aug. 1985). 